\title{
Erratum to: What Are the Predictors of Work Impairment in Iranian Patients with Depressive Disorders?
}

Gh. R. Ghassemi - Gh. H. Ahmadzadeh •

A. R. Yousefy $\cdot$ H. Fanian • V. Omranifard •

S. Mallik

Published online: 7 February 2010

(C) Springer Science+Business Media, LLC 2010

Erratum to: Community Ment Health J (2009) 45:453-462

DOI 10.1007/s10597-009-9254-z

Co-author's name had been wrongly published. The correct version is A. R. Yousefy and V. Omranifard not A. R. Usefy and V. Emarifard as published.

The online version of the original article can be found under doi:10.1007/s10597-009-9254-z .

Gh. R. Ghassemi $(\bowtie) \cdot$ A. R. Yousefy

Medical Education Research Centre, Isfahan University

of Medical Sciences, Isfahan, Iran

e-mail: ghassemi@med.mui.ac.ir

Gh. H. Ahmadzadeh · H. Fanian · V. Omranifard

Behavioural Sciences Research Centre, Isfahan University

of Medical Sciences, Isfahan, Iran

S. Mallik

Zenderood Clinic of Social Work, Isfahan, Iran 